\title{
Development of A Decellularized Meniscus Matrix-Based Nanofibrous Scaffold for Meniscus Tissue Engineering
}

${ }^{1}$ McKay Orthopaedic Research Laboratory, Department of Orthopaedic Surgery, Perelman

School of Medicine, University of Pennsylvania, Philadelphia, PA, USA

${ }^{2}$ Department of Bioengineering, School of Engineering and Applied Science, University of 11 Pennsylvania, Philadelphia, PA, USA

${ }^{3}$ Translational Musculoskeletal Research Center, Corporal Michael J Crescenz VA Medical 14 Center, Philadelphia, PA, USA

${ }^{4}$ Department of Pathology and Anatomical Sciences, Jacobs School of Medicine and Biomedical Sciences, University at Buffalo, State University of New York, Buffalo, NY, USA

Email: heosc@pennmedicine.upenn.edu

Short Title: dECM-based fibrous scaffolds for meniscus repair

Keywords: Decellularized extracellular matrix, Electrospinning, Meniscus 


\section{ABSTRACT}

2 The meniscus plays a critical role in knee mechanical function but is commonly injured given its

3 central load bearing role. In the adult, meniscus repair is limited, given the low number of

4 endogenous cells, the density of the matrix, and the limited vascularity. Menisci are

5 fibrocartilaginous tissues composed of a micro-/nano- fibrous extracellular matrix (ECM) and a

6 mixture of chondrocyte-like and fibroblast-like cells. Here, we developed a fibrous scaffold system

7 that consists of bioactive components (decellularized meniscus ECM (dME) within a poly(e-

8 caprolactone) material) fashioned into a biomimetic morphology (via electrospinning) to support

9 and enhance meniscus cell function and matrix production. This work supports that the

10 incorporation of dME into synthetic nanofibers increased hydrophilicity of the scaffold, leading to

11 enhanced meniscus cell spreading, proliferation, and fibrochondrogenic gene expression. This

12 work identifies a new biomimetic scaffold for therapeutic strategies to substitute or replace injured

13 meniscus tissue.

\section{STATEMENT OF SIGNIFICANCE}

17 In this study, we show that a scaffold electrospun from a combination of synthetic materials and

18 bovine decellularized meniscus ECM provides appropriate signals and a suitable template for

19 meniscus fibrochondrocyte spreading, proliferation, and secretion of collagen and proteoglycans.

20 Material characterization and in vitro cell studies support that this new bioactive material is 21 susceptible to enzymatic digestion and supports meniscus-like tissue formation. 


\section{INTRODUCTION}

2 Menisci are fibrocartilaginous tissues in the knee that transfer and redistribute load between the

3 femur and the tibia and provide secondary stability to the joint [1]. Given these vital functions in a

4 high load-bearing setting, menisci tears are common and occur in patients of all ages in various

5 locations and tear patterns [2-4]. Unfortunately, the meniscus also has a limited self-healing

6 capacity, given its dense composition and low cellularity and vascularity. Physical therapy and

7 arthroscopic partial meniscectomy are commonly performed to alleviate symptoms [5-7]. However,

8 these treatments do not restore the meniscus structure and function, and continued meniscus

9 insufficiency may precipitate the onset of osteoarthritis [8, 9]. Therefore, new therapeutic

10 strategies are needed to facilitate healing of meniscus injuries.

12 Over the past two decades, a number of load-bearing and/or pro-regenerative implants have 13 emerged as commercial products to treat the injured meniscus [10]. For instance, Menaflex ${ }^{\mathrm{TM}}[11$ -

14 14], a collagen-glycosaminoglycan (Collagen-GAG) meniscus replacement, as well as Actifit ${ }^{\mathrm{TM}}$ $15[11-14]$ and NUsurface ${ }^{\mathrm{TM}}[12,14]$, synthetic polycaprolactone-polyurethane (PCL-PU) or 16 polycarbonate-urethane (PCU) implants, are designed to either enhance meniscus ECM-like neo-

17 matrix production or improve load distribution in patients who have previously been subject to 18 partial or total meniscectomy. In addition, laboratory-based studies have developed regenerative 19 scaffolds that utilize decellularized meniscus ECM. Examples include using the whole piece of 20 lyophilized tissue directly as a graft [15-17], reconstituting pulverized tissue into porous or 21 hydrogel constructs [18-20], 3D printing with ECM-based bioinks [21-25], electrospinning from 22 solutions containing natural structural proteins similar to those present in the meniscus ECM [26-

23 28], or a combination of the above strategies [29, 30]. Many of the studies have demonstrated 24 improved meniscus cell or stem cell viability, infiltration, and neo-matrix deposition over time. 
1 However, there are limitations associated with each of the above approaches. In the cases of

2 decellularized whole meniscus transplantation, inadequate mechanical strength could lead to

3 construct ruptures and joint deterioration, and insufficient recellularization could hamper

4 chrondroprotective effects [15, 17]. While building bioactive scaffolds reconstituted from ECM

5 components on hydrogel extrusion or casting platforms could provide more flexibility in terms of

6 matching the gaps in various meniscus tears, the substrate stiffness and porosity need to be

7 meticulously tuned to encourage cell spreading and migration [18, 20]. Therefore, it is important

8 to devise a degradable material and fabrication method to make a scaffold that does not rupture

9 but still supports meniscus cell activities through its bioactive open pore surface features.

11 Electrospinning is an advanced fabrication technique widely used to produce scaffolding materials

12 that possess a nanofibrous structure comparable to the ECM of fibrous connective tissues.

13 Researchers have recently spun natural materials such as gelatin, collagen, and ECM together

14 with synthetic polymers to produce biomimetic scaffolds for repair and regeneration [26, 27, 31-

15 34]. These scaffolds are biocompatible and show enhanced cell adhesion and proliferation

16 compared to their purely synthetic counterparts, possibly due to enhanced hydrophilicity and

17 bioactivity of the scaffolds. One limitation to this strategy, however, is the use of toxic organic

18 solvents, for example, trifluoroethanol (TFE) and hexafluro-2-propanol (HFIP) in the preparation

19 of the electrospinning solution, which poses hazards to the researchers via inhalation and may

20 impede regulatory approval of these approaches [35-37]. Such methods could be improved by

21 the derivation and testing of "green" solvents, and the optimization of conditions under which such

22 solvents homogenize both natural and synthetic scaffold components.

24 To address this need, in this study, we developed a safe and efficient method to incorporate 25 decellularized bovine meniscus ECM as a biomimetic component within a nanofibrous scaffold. 
1 We then developed a process to fabricate a decellularized meniscus ECM/poly( $\varepsilon$-caprolactone)

2 (dMEP) nanofibrous scaffold for meniscus regeneration by co-electrospinning the homogenized

3 solution. Given that the scaffold will eventually be implanted in a hydrated in vivo environment,

4 we tested two common collagen crosslinkers, glutaraldehyde (GA) and genipin (GP), and

5 evaluated their ability to maintain fiber morphology, as well as their biocompatibility with meniscus

6 cells. We then compared these dMEP scaffolds with their PCL-only counterparts via a series of

7 material characterization tests and in vitro cell studies. We hypothesize that the dMEP scaffolds

8 would promote meniscus cell spreading, proliferation, and differentiation to a greater extent than

9 PCL-only scaffolds. And therefore, this novel combination of bioactive content with advanced

10 scaffold fabrication techniques may generate material frameworks that can optimally promote

11 meniscus tissue formation and regeneration.

\section{MATERIALS AND METHODS}

\section{$14 \quad 2.1 \quad$ Tissue Decellularization and Verification}

15 Decellularized meniscus ECM (dME) was generated using a protocol modified from Wu et al. [18].

16 In brief, menisci were harvested from juvenile bovine knee joints (Research 87, 2-3 months old)

17 and were minced into cubes of approximately $1 \mathrm{~mm}^{3}$ (Fig. $\left.1 \mathrm{~A} \mathrm{i}-\mathrm{ii}\right)$. To achieve decellularization,

18 meniscus cubes isolated from each meniscus were stirred in a $1 \%$ SDS/PBS $(\mathrm{w} / \mathrm{v})$ solution for 72

$19 \mathrm{~h}$, with the solution refreshed every $24 \mathrm{~h}$. Next, the tissue was washed in a $0.1 \%$ EDTA/PBS (w/v)

20 solution for $24 \mathrm{~h}$ (Fig. 1A iii). Finally, the tissue was rinsed in an excess of distilled water for $12 \mathrm{~h}$

21 and then lyophilized for $72 \mathrm{~h}$. Dried tissue was ground into fine powder using a freezer-mill

22 (SamplePrep $^{\mathrm{TM}} 6770$ Freezer/Mill ${ }^{\mathrm{TM}}$, precool time $=1 \mathrm{~min}$, runtime $=2 \mathrm{~min}$, rate $=14$

23 cycles/second). To verify that menisci were appropriately decellularized, the meniscus cubes pre

24 and post decellularization were fixed in phosphate buffered paraformaldehyde (PFA) at $4^{\circ} \mathrm{C}$

25 overnight, cleared in CitriSolv and embedded in paraffin for sectioning (thickness $=6 \mu \mathrm{m}$ ). Cell

26 removal was confirmed by hematoxylin and eosin (H\&E) staining and was quantified by counting 
1 the remaining nuclei on histological sections stained with 4,6-diamidino-2-phenylindole (DAPI) (n

$2=5$, imaged at $10 \mathrm{X}$ on a Nikon Ti inverted fluorescence microscope). Preservation of collagen

3 and proteoglycans in the decellularized tissue was determined via picrosirius red (PSR) and alcian

4 blue $(A B)$ staining, respectively [34, 38]. Images were captured with an Eclipse 90i upright

5 microscope.

$7 \quad 2.2$ Electrospinning decellularized meniscus ECM - polycaprolactone (dMEP) nanofibers

8 Electrospinning solutions were prepared using the protocol optimized from Binulal et al. and

9 contained both ECM and poly(ع-caprolactone) (PCL, 80kDa) [39]. Specifically, a 28\% w/v dMEP

10 (50:50) mixture was prepared by dissolving $1.4 \mathrm{~g}$ of $\mathrm{dME}$ powder in $10 \mathrm{~mL}$ of a diluted acidic

11 solution (Acetic Acid : Ethyl Acetate : $d d H 2 O(v / v / v)=3: 2: 1)$ at $45^{\circ} \mathrm{C}$ for three days. Next, 1.4

$12 \mathrm{~g}$ of PCL was added to the solution and stirred at the same temperature for an additional two days.

13 Nanofibrous scaffolds were produced via electrospinning at a voltage of $15 \mathrm{kV}$, a needle-to-

14 collector distance of $9 \mathrm{~cm}$, and a flow rate of $2.2 \mathrm{~mL} / \mathrm{h}$, with randomly-organized fibers collected

15 onto a grounded mandrel rotating at a slow speed. Relative humidity was maintained between

$1619 \%-24 \%$. Additional electrospun PCL-only scaffolds were spun with a similar average fiber

17 diameter and alignment as a control. For this, $2.4 \mathrm{~g}$ of PCL was dissolved in $10 \mathrm{~mL}$ of Acetic

18 Acid/Ethyl Acetate (1:1) solution at $45^{\circ} \mathrm{C}$ for two days. Afterwards, this solution was electrospun

19 at a voltage of $15 \mathrm{kV}$, a needle-to-collector distance of $14 \mathrm{~cm}$ and a flow rate of $2.2 \mathrm{~mL} / \mathrm{h}$. The

20 scaffolds were removed from the mandrel and maintained in a vacuum chamber at room

21 temperature prior to further analysis $[18,40]$.

\section{$23 \quad 2.3 \quad$ Crosslinking and Morphological Observation of dMEP Nanofibers}

24 Due to the instability of collagen and GAG in an aqueous environment, an effective crosslinker is

25 required to keep the scaffolds intact [41-44]. To accomplish this, two collagen crosslinkers were

26 tested: glutaraldehyde (GA, Sigma-Aldrich) and genipin (GP, Wako Chemicals and Challenge 
1 Bioproduct). The dMEP scaffolds were either punched into rounds $(\varnothing=1 \mathrm{~cm})$ for surface

2 characterization and cell studies or cut into strips (40 $\mathrm{mm} \times 5 \mathrm{~mm})$ for mechanical testing and

3 histological analysis. For GA crosslinking, samples were incubated in a chamber containing 50:50

$4 \mathrm{GA}: \mathrm{dH}_{2} \mathrm{O}$ vapor at $25^{\circ} \mathrm{C}$ for $48 \mathrm{~h}$ and quenched in $0.1 \mathrm{M}$ glycine for $1 \mathrm{~h}$. For GP crosslinking,

5 samples were submersed in $0.4 \mathrm{M} \mathrm{GP}$ ethanol solution at $37^{\circ} \mathrm{C}$ for $48 \mathrm{~h}$. Both the dMEP and

6 control (24\% PCL only) groups were rehydrated in a series of $\mathrm{EtOH} / \mathrm{dH}_{2} \mathrm{O}$ solutions with

7 graduated, sequentially decreasing concentrations (100\% to $0 \%)$ for further material

8 characterization and in vitro cell studies [33]. Samples were not directly matched (paired) in these

9 studies, though all were derived from the same fabrication runs.

\subsection{Analysis of dMEP Nanofibers with Scanning Electron Microscopy}

12 The surface morphology of the scaffolds before and after crosslinking was examined by sputter

13 coating the samples with $8 \mathrm{~nm}$ of iridium on an EMS Quorum Q150T ES sputter coater, then

14 imaging with an FEI Quanta FEG 250 scanning electron microscope (SEM) at a distance of 10

$15 \mathrm{~mm}$ and magnification of 1000x. Comparison of fiber diameters were done via manual contouring

16 and measurement in FIJI [45].

$18 \quad 2.5 \quad$ In vitro Enzymatic Degradation of dMEP Nanofibers

19 To explore the degradation behavior of dMEP scaffolds, acellular PCL and GA or GP crosslinked

20 dMEP scaffolds ( $n=4 /$ group) were digested in $2 \mathrm{mg} / \mathrm{mL}$ collagenase type 2 solution (Worthington)

21 for $24 \mathrm{~h}$ at $37^{\circ} \mathrm{C}$, and then digested in $100 \mathrm{ug} / \mathrm{mL}$ proteinase $\mathrm{K}$ in tris- $\mathrm{HCl}$ overnight at $60^{\circ} \mathrm{C}$. A

22 scaffold from each group was used for SEM imaging to visualize changes in fiber morphology and

23 structure after enzymatic degradation, and the remaining were used for the orthohydroxyproline

24 (OHP) assay to quantify remaining collagen [46]. These scaffolds were compared against 
1 scaffolds from each group that were not collagenase-treated through both SEM assessment and

2 the OHP assay.

\section{$4 \quad 2.6 \quad$ Assessment of Scaffold Hydrophilicity}

5 Hydrophilicity, or surface wettability, may influence the composition of the adsorbed protein layer,

6 which could in turn regulate how cells respond to the material [47]. Thus, contact angle analysis

7 was performed to compare the surface wettability of the dMEP nanofibrous scaffold to the PCL-

8 only scaffold, after rehydration and air-drying ( $n=4$ /group). A drop of $10 \mu \mathrm{L} \mathrm{dH} 2 \mathrm{O}$ was gently

9 deposited onto a piece of air-dried scaffold (diameter $=1 \mathrm{~cm}$ ) and time lapse images were taken

10 for 90 seconds at 30 second intervals. Contact angle was measured using the angle tool in Image J

$11[45]$.

\section{$13 \quad 2.7 \quad$ Mechanical Evaluation of Scaffolds}

14 Uniaxial tensile testing was performed on rectangular-shaped dMEP and PCL-only scaffold strips

15 (size $=40 \mathrm{~mm} \times 5 \mathrm{~mm}, \mathrm{n}=6-7 /$ group). A dry (before crosslinking) scaffold group and a wet (after

16 crosslinking) scaffold group were included in this analysis. The thickness and width of the scaffold

17 were measured using a custom laser thickness measurement system, and the average cross-

18 sectional area was calculated with a MATLAB code $[33,46]$ (shown in S Fig. 3). The test samples

19 were then gripped at both ends on an Instron 5542 material testing system with a gauge length

20 of $20 \mathrm{~mm}$. Samples were extended to failure at a constant strain rate of $0.2 \% / \mathrm{sec}$. The elastic

21 modulus was calculated from the linear region of the stress-strain curve [40].

\section{$23 \quad 2.8 \quad$ Assessment of Cell Adhesion and Proliferation}

24 To evaluate cell adhesion and proliferation on the scaffolds, bovine meniscus fibrochondrocytes

25 (bMFCs) were isolated from the outer region of freshly isolated medial and lateral juvenile (2-3

26 months) bovine meniscus tissue and expanded to passage 2 (P2) prior to seeding [40, 48]. After 
1 rehydration and triple-rinsing in sterile PBS, the dMEP composite GA-crosslinked and GP-

2 crosslinked, and PCL-only scaffolds were UV sterilized for 30 minutes prior to cell seeding. To

3 asses cell adhesion and spreading, 500 bMFCs were seeded onto each patch $(\varnothing=1 \mathrm{~cm})$,

4 submerged in a chemically defined growth factor-free media (High glucose Dulbecco's minimal

5 essential medium (DMEM), 0.1mM Dexamethasome, 50ug/mL Ascorbate-2-Phosphate, 40ug/mL

6 L-Proline, 100ug/mL Sodium Pyruvate, ITS+ Premix, 1\% penicillin/streptomycin/fungizone (PSF),

$71.25 \mathrm{mg} / \mathrm{mL}$ bovine serum albumin (BSA), and 5.3ug/mL linoleic acid) $[38,48]$, and incubated at

$837^{\circ} \mathrm{C}$ under $5 \% \mathrm{CO}_{2}$ for 1 , 3, or 6 hours. At each time point, cells were fixed in $4 \%$

9 paraformaldehyde (PFA) and stained with Alexa Fluor 488 Phalloidin to visualize the cytoskeleton.

10 To quantify cell spreading, images were captured at 20x magnification on a Leica DM 6000

11 widefield microscope and cell area, aspect ratio, and solidity were analyzed in FIJI using these

12 images ( $n=27-30 /$ group/time point) [51].

14 Cell proliferation on the PCL-only and dMEP scaffolds was evaluated using a cell counting kit

15 (Cell Counting Kit - 8 (CCK-8), Sigma) [33, 34]. Prior to CCK-8 assay, bMFCs were seeded onto

16 the round patches $(\varnothing=1 \mathrm{~cm}, 5000$ cells/patch, $n=6 /$ group), submerged in growth factor-free

17 media (DMEM $+1 \%$ PSF $+10 \%$ fetal bovine serum), and incubated at $37^{\circ} \mathrm{C}$ and $5 \%$ CO2 for 1 or

183 days. At the end of the incubation period, each scaffold was submerged in the CCK-8 reagent

19 in a 96 -well plate at $37^{\circ} \mathrm{C}$ for $2 \mathrm{~h}$, and the absorbance (which is directly proportional to living cell

20 population) was read on a Synergy $\mathrm{H} 1$ microplate reader at $450 \mathrm{~nm}$.

22 To evaluate cell viability on scaffolds, 20,000 P2 bMFCs were seeded onto round scaffold patches

23 and incubated in basal growth media for 1 or 7 days. On the day of imaging, the scaffolds were

24 submerged in a Live/Dead staining solution (PBS : EH: Calcein-AM $=1 \mathrm{~mL}: 2 \mu \mathrm{L}: 0.5 \mu \mathrm{L}$, Sigma)

25 for 45 minutes at $37^{\circ} \mathrm{C}$, and imaged with a Leica DM 6000 widefield. 


\subsection{Assessment of Transcriptional Activation and Gene Expression}

3 To assess the influence of the dMEP scaffold on transcriptional activities in cells, 500 bMFCs

4 were seeded onto scaffolds $(\varnothing=1 \mathrm{~cm})$ and incubated in basal growth media for $24 \mathrm{~h}$. Afterwards,

5 they were permeabilized and fixed in a freezing cold methanol/ethanol (50:50) solution for 6

6 minutes. Samples were then blocked with $1 \%$ BSA, followed by a triple rinse in PBS before

7 immunofluorescence staining. Cells were stained first with transcriptional activation markers,

8 Acetyl-H3K9 (AC-H3K9) (Invitrogen \# MA5-11195, 1:400) or RNA polymerase II (POL-II)

9 (Invitrogen \# MA5-23510, 1:500) for $1 \mathrm{~h}$ at room temperature [50, 51]. Next, after a triple rinse,

10 Alexa Fluor 488 goat anti-rabbit secondary antibody (Invitrogen A-11008, 1:200) or Alexa Fluor

11546 goat anti-mouse secondary antibody (Invitrogen A-11030, 1:200), respectively, was added at

12 room temperature for an additional hour [25, 26]. Images were captured at $100 x$ magnification

13 using a Leica DM 6000 widefield microscope and fluorescence intensity was analyzed in FIJI (n

$14=18-22 /$ group) [51].

16 For fibrochondrogenic gene expression analysis, 5,000 bMFCs were seeded onto the scaffolds

17 and cultured in a chemically defined media containing $10 \mathrm{ng} / \mathrm{mL}$ TGF- $\beta 3$ for one week $\varnothing=1 \mathrm{~cm}$,

$18 \mathrm{n}=6$ /group) $[33,38,48]$. RNA was extracted from samples preserved in TRIzol ${ }^{\mathrm{TM}}$ Reagent

19 (Invitrogen), and mRNA was quantified on an ND-100 Nanodrop Spectrometer. cDNA was

20 synthesized using a SuperScript ${ }^{\mathrm{TM}}$ IV First-Strand Synthesis System (Invitrogen), and amplified

21 using an Applied Biosystems Step One Plus real-time PCR system. Amplification curves for

22 Collagen I, Collagen II, Aggrecan and CTGF were analyzed in the linear region of the amplification

23 and normalized against the housekeeping gene glyceraldehyde-3-phosphate dehydrogenase

24 (GAPDH) [34, 49]. 


\subsection{Assessment of Matrix Content}

2 To evaluate matrix production and dECM retention in and on the scaffolds over time, 5,000 bMFCs

3 were seeded onto three groups of scaffolds $(40 \mathrm{~mm} \times 5 \mathrm{~mm})$ and incubated in a chemically-

4 defined culture media containing TGF- $\beta 3$ for up to 4 weeks. At each time point, the scaffolds were

5 removed, dried, and weighed on an analytical balance ( $n=5-6 /$ group). The scaffolds were then

6 digested in $100 \mathrm{ug} / \mathrm{mL}$ proteinase $\mathrm{K}$ in tris- $\mathrm{HCL}$ overnight at $60^{\circ} \mathrm{C}$. After that, the $\mathrm{OHP}$ assay was

7 performed for collagen quantification and 1,9-dimethylmethylene blue (DMMB) assay was

8 performed for GAG quantification [46, 52]. DNA content in the digest was quantified with the

9 Quant-iT ${ }^{\mathrm{TM}}$ PicoGreen ${ }^{\mathrm{TM}}$ dsDNA assay (Invitrogen).

112.11 Statistical analyses

12 Statistical tests were performed in the PRISM 8 software. Specific analyses included a t-test to 13 confirm decellularization, compared scaffold mechanical strength (before crosslinking), evaluated

14 chondrogenic gene expression. For other outcomes with multiple groups, a one-way ANOVA was

15 used to compare fiber diameter, OHP content following collagenase treatment, scaffold 16 mechanical strength (after crosslinking), and transcriptional activation. For other outcomes, a 17 two-way ANOVA was used to assess differences in hydrophilicity, cell adhesion, long term matrix 18 content. Either Tukey's or Kruskal-Wallis post hoc comparisons were used with a confidence 19 interval of $95 \%$.

\section{RESULTS}

$22 \quad 3.1$ Characterization of Decellularized ECM

23 After the decellularization process, cell removal in the meniscus ECM was first confirmed by

24 counting the remaining DAPI stained nuclei or visualizing nuclei by H\&E staining of histological

25 sections. While the freshly harvested juvenile meniscus tissue contained a large number of 26 fibrochondrocyte-like cells (MFCs), DAPI staining showed that the cells were effectively removed 
1 from the tissue with the decellularization process, with $0.5 \%$ of the nuclei remaining in five

2 biological replicate groups. Effective cell removal was also confirmed by H\&E staining (Fig. 1B).

3 The collagen content and architecture were preserved after the decellularization treatment (Fig.

4 1C, top row). In contrast, there was a noticeable decrease in alcian blue staining intensity,

5 indicating a loss of proteoglycan content with decellularization (Fig. 1C, bottom row).

$7 \quad 3.2 \quad$ Electrospun dMEP Nanofibers

8 To fabricate nanofibrous scaffolds containing decellularized native meniscus ECM, the dMEP

9 mixture was prepared and electrospun (Fig. 2A). Suitable formulations were selected based on

10 the ability to spin a scaffold without interruption of fiber formation, appropriate fiber diameter in

11 the collected scaffold, and the lack of irregularities/inclusions in the formed mat, which are

12 indicative of an unstable Taylor cone.

\section{$14 \quad 3.3 \quad$ Assessment of Fiber morphology via SEM}

15 The nanostructure of the electrospun scaffolds pre- and post-crosslinking was examined by 16 scanning electron microscopy (SEM). Fiber diameter and orientation of the uncrosslinked and dry

17 dMEP scaffold were similar $(p>0.05)$ to those of the PCL control scaffold (Fig. 2B i-ii, 2C). SEM

18 images demonstrated that crosslinking with either GA or GP preserved the fibrous morphology,

19 while hydration of uncrosslinked dMEP scaffolds resulted in substantial changes in fibrous

20 morphology (Fig. 2B iii-v). There was minimal batch to batch variability in terms of fiber diameter

21 for dMEP scaffolds electrospun on different dates under the same conditions (S Fig. 1)

\section{$23 \quad 3.4 \quad$ Assessment of Collagen Content in dMEP Nanofibers}

24 The initial collagen content of dMEP nanofibers was considerably higher than PCL nanofibers.

25 This was verified by collagenase treatment of the dMEP fibers, where the collagen content 26 decreased 10-fold after collagenase treatment $(p<0.05)$ [Col(+), Fig. 2D]. This finding also 
1 suggests that this biomimetic component of the dMEP fibers is accessible and may be degraded

2 by collagenase secreted by endogenous meniscus cells or cells seeded onto the scaffold. dMEP

3 nanofibers were straighter after collagenase treatment, with a decrease in fiber diameter,

4 suggesting there might have been some amount of pre-tension within fibers as a result of the

5 electrospinning and crosslinking process (S Fig. 2).

\subsection{Assessment of Scaffold Hydrophilicity}

8 The hydrophilicity of a scaffold is an important factor for cell attachment, spreading, and

9 proliferation [53] and also affects oxygen and nutrient transfer within the scaffold [54]. The

10 wettability test showed a decrease of the contact angle over time for all three groups. Water was

11 absorbed into the dMEP scaffold more rapidly $(p<0.05)$ than the PCL scaffold (Fig. 3A), indicating

12 that the addition of $\mathrm{dECM}$ improved hydrophilicity. Of note, the initial contact angle for the PCL

13 scaffolds were higher than for the dMEP scaffold with either GA or GP crosslinking $(p<0.05$, Fig.

14 3B), and this relationship was conserved for final water contact angles measured at 90 seconds.

$16 \quad 3.6 \quad$ Mechanical Strength of Scaffolds

17 Additionally, crosslinking and rehydration process altered the mechanical properties of dMEP

18 scaffolds (Fig $\mathbf{4 A}$, individual curves in S Fig. 3A), in particular, ductility of dMEP scaffold was

19 enhanced by the crosslinking process. The average tensile modulus $(p<0.05)$ and ultimate tensile

20 strength $(p=0.09)$ of the dry of uncrosslinked dMEP scaffolds were higher than those of the PCL

21 scaffolds (Fig. 4B). After crosslinking and rehydration, however, the modulus and ultimate tensile

22 strength of the wet PCL scaffold were 2-3 times higher than either crosslinked dMEP scaffold

$23(\mathrm{p}<0.05)$, whose moduli were similar to one another $(\sim 0.5 \mathrm{MPa}$, Fig. $4 \mathrm{C})$. 


\section{$1 \quad 3.7$ Assessment of Cell Spreading and Proliferation}

2 Actin staining showed the meniscus cells attached to all 3 scaffolds over 6 hours of incubation in

3 chemically defined serum free media. While bMFCs spread similarly on all three scaffolds, they

4 spread more on the dMEP scaffolds, according to increased cell area (Fig. 5A, B, p<0.05). The

5 cell aspect ratios were also slightly lower for dMEP scaffolds at all time points, and those cells

6 seeded on dMEP scaffolds elongated faster (Fig. 5A, B). Moreover, bMFCs proliferated faster on

7 dMEP scaffolds over the course of 3 days $(p<0.05)$ (Fig. 5C). Taken together, these data suggest

8 the dMEP scaffolds improve cell spreading and proliferation compared to PCL-only scaffolds.

\section{$10 \quad 3.8$ Assessment of Transcriptional Activation and Gene Expression}

11 Compared to the PCL scaffolds, the fluorescence intensity of both AC-H3K9 or POL-II

12 transcriptional activation makers [50] was higher in the bMFCs cell nuclei seeded on dMEP

13 scaffolds $(p<0.05)$ (Fig. 6A, B). Further, the expression of type-I collagen (Col I), type-II collagen

14 (Col II), aggrecan (AGC) and connective tissue growth factor (CTGF) were all 20\% higher in

15 cells on dMEP scaffolds compared to cells on PCL control scaffolds at 1 week (Fig. 6C, $p<0.05)$.

16 Live and dead staining showed that the viability of cells was high $24 \mathrm{~h}$ post seeding and was

17 further enhanced by the dMEP scaffold crosslinked by GP (S Fig. 4).

\section{$19 \quad 3.9 \quad$ Matrix Deposition with Long term Culture}

20 MFCs seeded onto all scaffold groups proliferated steadily in growth factor-containing media, with

21 only minor difference in proliferation rate over the course of 4 weeks (s Fig. 5). Total collagen

22 content was higher in bMFC-seeded dMEP scaffolds compared to PCL-only, though the

23 magnitude of this differences decreased over time (Fig. 7A). The same trend was noted after

24 normalization by sample weight (Fig. 7B). Since the collagen concentration in the dMEP scaffolds

25 was initially quite high, this may suggest that the collagen within the scaffold was being broken 
1 down by the cells during culture at a rate higher than the secretion and accumulation of new

2 collagen, leading to a decreasing total amount. Total GAG content in PCL/ECM cell-seeded

3 scaffolds increased slightly over 4 weeks, with a similar trend observed post normalization by

4 sample weight (Fig. 7C-D). Considering that the initial GAG content in the scaffolds was very low,

5 it is likely that the majority of GAG detected in this assay was new matrix produced by cells during

6 the incubation phase. Noticeability, collagen amount was stable in acellular dMEP scaffolds (s

7 Fig. 6), indicating that the majority of collagen detected in the OHP assay came from the scaffold,

8 instead of being newly secreted by seeded cells.

\section{DISCUSSION}

11 In this study, we established a protocol to successfully extract decellularized meniscus ECM (dME)

12 content. We then combined this material with a synthetic polymer (PCL) to fabricate a nanofibrous

13 scaffold for meniscus repair. PCL was chosen among a library of biodegradable polymers for its

14 distinct material properties; it has can be deformed elastically through physiological levels, while

15 at the same time being degradable via enzymatic or hydrolytic mechanisms [55]. By

16 electrospinning the $(\mathrm{dME})$ material combined with the synthetic polymer from a single jet and then

17 subsequently crosslinking the thick mat, we generated a native dME-containing nanofibrous

18 scaffold with a similar fibrous structure to the native meniscus. Compared to the pure polymer

19 construct, the dMEP nanofibers were more hydrophilic and bioactive, promoting cell attachment

20 and spreading at early time points. This finding supports our hypothesis that the inclusion of dME

21 content enhances substrate hydrophilicity (and may regulate protein adsorption) to guide initial

22 cell attachment [56-57]. This finding is consistent with previous studies that created dME based

23 scaffolds for musculoskeletal tissue repair (e.g. bone, muscle, tendon), in which evidence of dME

24 promoting recellularization and organic molecule adsorption had been reported [57-59]. We also

25 confirmed that dMEP scaffolds contained a significantly higher initial collagen components than

26 the PCL scaffolds, and that this component was accessible to exogenous proteases. This 
1 indicates that the hybrid synthetic-biomimetic fibers can be acted on and digested by cell-

2 produced collagenase.

3 With these early observations in hand, we next proceeded to longer-term evaluation. These

4 studies confirmed that the collagen and GAG content not only started higher, but remained

5 elevated in dMEP scaffolds over time, compared to synthetic PCL-only scaffolds. This indicates

6 that the crosslinking utilized was effective at maintaining the dME content with culture, and that

7 seeded meniscus cells secreted additional matrix over time. GA and GP had comparable effects

8 in preserving dMEP fibrous morphology and strength, retaining collagen content, modifying

9 surface wettability, and promoting cell expansion and proliferation. However, the GA group

10 exhibited higher transcriptional activation of $\mathrm{AC}-\mathrm{H} 3 \mathrm{~K} 9$ and POL-II than the GP group. This

11 observation is consistent with previous studies in which the impact of crosslinkers on tissue

12 mechanics and cellular activities were examined [33,60]. Meniscus cells also proliferated to a

13 greater extent on dMEP scaffolds and showed higher viability compared to the synthetic PCL-

14 only scaffold, confirming the biocompatibility of the scaffold. The inclusion of dECM also enhanced

15 both transcriptional activation (determined by epigenetic markers) and fibrochondrogenic gene

16 expression (determined by RT-PCR) of meniscus cells. After 1 day, meniscus cells showed

17 increased marks for RNA transcription overall, and by one week, showed higher levels of mRNA

18 for collagen I, II, CTGF, and aggrecan. These data indicate that dME inclusion in the dMEP

19 scaffold promotes initial cell activity, and that this translates into an enhanced meniscus-specific

20 gene expression profile at one week However, these assessments of transcriptional activation

21 and gene expression will need to be compared to expression by cells in the native meniscus, and

22 should be expanded to include ECM degrading enzymes [60] and/or proinflammatory cytokines

$23[61]$.

24 This study established the potential of dME inclusion to create biohybrid scaffolds which work to 25 promote meniscus cell phenotype over long term culture and provides a foundation for further 
1 refinement and translation. One limitation of the scaffold is its physical properties: it is a sheet-

2 based scaffold with an elastic modulus that is $\sim 3.5 \%$ of the elastic modulus of the radial region of

3 the juvenile meniscus, and the ultimate strength of the scaffold is $\sim 20 \%$ of native [63]. Therefore,

4 the dMEP scaffold would be most useful in situations where structural support is less necessary

5 or after tissue deposition and scaffold maturation has occurred in vitro prior to implantation [64].

6 However, since we only explored one material fabrication technique (electrospinning), these

7 results may be further integrated into technologies for generating meniscus-shaped constructs.

8 For example, these fibers might be woven into thicker and aligned microfibers to further mimic

9 the hierarchical structure of the native tissue and to reinforce its overall and directional mechanical

10 properties [65-68]. Another important feature of the scaffolds was shown in the collagenase

11 treatment experiment, where the dMEP fibers were thinner post-collagenase treatment (perhaps

12 as a result of the collagen content being digested). Remodeling capacity is an important feature

13 in any scaffold, and here cell-generated proteases may act on the dMEP scaffold to generate

14 more space for cell infiltration [20]. To better characterize these remodeling dynamics, future ex

15 vivo studies will assess the stability of the dMEP scaffold over a longer term. Importantly, however,

16 since the remaining PCL component would be unaffected by digestion, it could continue to provide

17 structural support during regeneration. Another feature that may be considered in the future is the

18 heterogeneous nature of the meniscus itself, where there are inner and outer zones with distinct

19 cell phenotypes and ECM composition [69-70]. This dMEP scaffolding system could be further

20 refined to include zonal dME with various protein compositions to provide meniscus zone specific

21 attributes and biological cues to infiltrating cells. Finally, through our longer-term evaluations, we

22 confirmed that fibrocartilaginous matrix concentrations in the dMEP scaffold were high and stable

23 during the culture periods, and that seeded cells produced new matrix. However, the balance

24 between retention and production of neo-matrix by meniscus cells will need to be further

25 evaluated in vivo to examine the performance of this scaffold in a physiologically relevant

26 environment. Taken together, this novel combination of bioactive content with advanced scaffold 
1 fabrication generated a new translational material that can be further optimized to improve

2 meniscus matrix formation and functional regeneration.

\section{ACKNOWLEDGEMENTS}

This work was supported by the National Institutes of Health (R01 AR056624, K01 AR077087, R21AR077700), the Penn Center for Musculoskeletal Disorders (P30 AR069619), and the Department of Veterans Affairs (IK6 RX003416). The authors would like to acknowledge Dr. Jay Patel for discussions on experimental design, the CDB microscopy core for assistance with microscopy, Emilie Rabut for help with the freezer-mill, and Cheryl Wecksler for input on scientific language. 


\section{REFERENCES}

1. A.J.S. Fox, A. Bedi, S.A. Rodeo, The basic science of human knee menisci: structure, composition, and function, Sports Health. 4 (2012) 340-351.

2. A. Moraux, C. Khalil, X. Demondion, A. Cotten, Inferiorly displaced flap tear of the medial meniscus: sonographic diagnosis, J. Ultrasound Med. 27 (2008) 1795-1798.

3. T.J. Ridley, M.A. McCarthy, M.J. Bollier, B.R. Wolf, A. Amendola, Age Differences in the Prevalence of Isolated Medial and Lateral Meniscal Tears in Surgically Treated Patients, lowa Orthop. J. 37 (2017) 91-94.

4. B. Day, W.G. Mackenzie, S.S. Shim, G. Leung, The vascular and nerve supply of the human meniscus, Arthroscopy. 1 (1985) 58-62.

5. R. Howell, N.S. Kumar, N. Patel, J. Tom, Degenerative meniscus: Pathogenesis, diagnosis, and treatment options, World J. Orthop. 5 (2014) 597-602.

6. N. Maffulli, Meniscal tears, Open Access Journal of Sports Medicine. (2010) 45. https://doi.org/10.2147/oajsm.s7753.

7. M.N. Doral, O. Bilge, G. Huri, E. Turhan, R. Verdonk, Modern treatment of meniscal tears, EFORT Open Rev. 3 (2018) 260-268.

8. R. Verdonk, H. Madry, N. Shabshin, F. Dirisamer, G.M. Peretti, N. Pujol, T. Spalding, P. Verdonk, R. Seil, V. Condello, B. Di Matteo, J. Zellner, P. Angele, The role of meniscal tissue in joint protection in early osteoarthritis, Knee Surg. Sports Traumatol. Arthrosc. 24 (2016) 1763-1774.

9. J.N. Katz, S.A. Brownlee, M.H. Jones, The role of arthroscopy in the management of knee osteoarthritis, Best Pract. Res. Clin. Rheumatol. 28 (2014) 143-156.

10. J.A. Schwartz, W. Wang, T. Goldstein, D.A. Grande, Tissue Engineered Meniscus Repair, CARTILAGE. 5 (2014) 165-171. https://doi.org/10.1177/1947603514526038.

11. E. Bulgheroni, A. Grassi, M. Campagnolo, P. Bulgheroni, A. Mudhigere, A. Gobbi, Comparative Study of Collagen versus Synthetic-Based Meniscal Scaffolds in Treating Meniscal Deficiency in Young Active Population, Cartilage. 7 (2016) 29-38.

12. J. Sun, S. Vijayavenkataraman, H. Liu, An Overview of Scaffold Design and Fabrication Technology for Engineered Knee Meniscus, Materials. 10 (2017) 29. https://doi.org/10.3390/ma10010029.

13. S. Dangelmajer, F. Familiari, R. Simonetta, M. Kaymakoglu, G. Huri, Meniscal Transplants and Scaffolds: A Systematic Review of the Literature, Knee Surg. Relat. Res. 29 (2017) 3-10.

14. K. Vadodaria, A. Kulkarni, E. Santhini, P. Vasudevan, Materials and structures used in meniscus repair and regeneration: a review, Biomedicine. 9 (2019) 2. 
15. K. Gelse, L. Körber, M. Schöne, K. Raum, P. Koch, M. Pachowsky, G. Welsch, R. Breiter, Transplantation of Chemically Processed Decellularized Meniscal Allografts: A Pilot Sheep Study, Cartilage. 8 (2017) 180-190.

16. K. Shimomura, B.B. Rothrauff, R.S. Tuan, Region-Specific Effect of the Decellularized Meniscus Extracellular Matrix on Mesenchymal Stem Cell-Based Meniscus Tissue Engineering, Am. J. Sports Med. 45 (2017) 604-611.

17. D. Jiang, Z.-Z. Zhang, F. Zhao, S.-J. Wang, Y.-S. Qi, L.-H. Zhao, J.-Y. Zhang, J.-K. Yu, The Radiated Deep-frozen Xenogenic Meniscal Tissue Regenerated the Total Meniscus with Chondroprotection, Sci. Rep. 8 (2018) 9041.

18. J. Wu, Q. Ding, A. Dutta, Y. Wang, Y.-H. Huang, H. Weng, L. Tang, Y. Hong, An injectable extracellular matrix derived hydrogel for meniscus repair and regeneration, Acta Biomater. 16 (2015) 49-59.

19. X. Yuan, Y. Wei, A. Villasante, J.J.D. Ng, D.E. Arkonac, P.-H.G. Chao, G. VunjakNovakovic, Stem cell delivery in tissue-specific hydrogel enabled meniscal repair in an orthotopic rat model, Biomaterials. 132 (2017) 59-71.

20. J.C. Ruprecht, T.D. Waanders, C.R. Rowland, J.F. Nishimuta, K.A. Glass, J. Stencel, L.E. DeFrate, F. Guilak, J.B. Weinberg, A.L. McNulty, Meniscus-Derived Matrix Scaffolds Promote the Integrative Repair of Meniscal Defects, Sci. Rep. 9 (2019) 8719.

21. F. Pati, J. Jang, D.-H. Ha, S. Won Kim, J.-W. Rhie, J.-H. Shim, D.-H. Kim, D.-W. Cho, Printing three-dimensional tissue analogues with decellularized extracellular matrix bioink, Nat. Commun. 5 (2014) 3935.

22. G. Ahn, K.-H. Min, C. Kim, J.-S. Lee, D. Kang, J.-Y. Won, D.-W. Cho, J.-Y. Kim, S. Jin, W.-S. Yun, J.-H. Shim, Precise stacking of decellularized extracellular matrix based 3D cell-laden constructs by a 3D cell printing system equipped with heating modules, Sci. Rep. 7 (2017) 8624.

23. Y. Yang, Z. Chen, X. Song, Z. Zhang, J. Zhang, K.K. Shung, Q. Zhou, Y. Chen, Biomimetic Anisotropic Reinforcement Architectures by Electrically Assisted Nanocomposite 3D Printing, Adv. Mater. 29 (2017). https://doi.org/10.1002/adma.201605750.

24. S.P. Grogan, P.H. Chung, P. Soman, P. Chen, M.K. Lotz, S. Chen, D.D. D'Lima, Digital micromirror device projection printing system for meniscus tissue engineering, Acta Biomater. 9 (2013) 7218-7226.

25. S.E. Bakarich, R. Gorkin 3rd, M. in het Panhuis, G.M. Spinks, Three-dimensional printing fiber reinforced hydrogel composites, ACS Appl. Mater. Interfaces. 6 (2014) 1599816006.

26. J. Baek, S. Sovani, N.E. Glembotski, J. Du, S. Jin, S.P. Grogan, D.D. D'Lima, Repair of Avascular Meniscus Tears with Electrospun Collagen Scaffolds Seeded with Human Cells, Tissue Engineering Part A. 22 (2016) 436-448. https://doi.org/10.1089/ten.tea.2015.0284. 
27. E. Venugopal, N. Rajeswaran, K.S. Sahanand, A. Bhattacharyya, S. Rajendran, In vitro evaluation of phytochemical loaded electrospun gelatin nanofibers for application in bone and cartilage tissue engineering, Biomed. Mater. 14 (2018) 015004.

28. B.B. Mandal, S.-H. Park, E.S. Gil, D.L. Kaplan, Multilayered silk scaffolds for meniscus tissue engineering, Biomaterials. 32 (2011) 639-651.

https://doi.org/10.1016/j.biomaterials.2010.08.115.

29. J. Baek, X. Chen, S. Sovani, S. Jin, S.P. Grogan, D.D. D'Lima, Meniscus tissue engineering using a novel combination of electrospun scaffolds and human meniscus cells embedded within an extracellular matrix hydrogel, J. Orthop. Res. 33 (2015) 572583.

30. Z. Yu, J. Lili, Z. Tiezheng, S. Li, W. Jianzhuang, D. Haichao, S. Kedong, L. Tianqing, Development of decellularized meniscus extracellular matrix and gelatin/chitosan scaffolds for meniscus tissue engineering, Biomed. Mater. Eng. 30 (2019) 125-132.

31. W. Fu, X. He, B. Feng, C. Huang, H. Wang, Y. Ge, R. Hu, M. Yin, Z. Xu, W. Wang, J. Zheng, Electrospun gelatin/polycaprolactone nanofibrous membranes combined with a coculture of bone marrow stromal cells and chondrocytes for cartilage engineering, International Journal of Nanomedicine. (2015) 2089. https://doi.org/10.2147/ijn.s79461.

32. P. Li, W. Zhang, H. Yu, L. Zheng, L. Yang, G. Liu, C. Sheng, H. Gui, S. Ni, P. Li, F. Shi, Applying Electrospun Gelatin/Poly(lactic acid-co-glycolic acid) Bilayered Nanofibers to Fabrication of Meniscal Tissue Engineering Scaffold, Journal of Nanoscience and Nanotechnology. 16 (2016) 4718-4726. https://doi.org/10.1166/jnn.2016.12412.

33. A.O. Gee, B.M. Baker, A.M. Silverstein, G. Montero, J.L. Esterhai, R.L. Mauck, Fabrication and evaluation of biomimetic-synthetic nanofibrous composites for soft tissue regeneration, Cell Tissue Res. 347 (2012) 803-813.

34. S. Gao, W. Guo, M. Chen, Z. Yuan, M. Wang, Y. Zhang, S. Liu, T. Xi, Q. Guo, Fabrication and characterization of electrospun nanofibers composed of decellularized meniscus extracellular matrix and polycaprolactone for meniscus tissue engineering, Journal of Materials Chemistry B. 5 (2017) 2273-2285. https://doi.org/10.1039/c6tb03299k.

35. J.M. Fraser, L.S. Kaminsky, Metabolism of 2,2,2-trifluoroethanol and its relationship to toxicity, Toxicology and Applied Pharmacology. 89 (1987) 202-210. https://doi.org/10.1016/0041-008x(87)90041-x.

36. D.A. Keller, G.L. Kennedy Jr, P.E. Ross, D.P. Kelly, G.S. Elliott, Toxicity of tetrafluoroethylene and S-(1, 1, 2, 2-tetrafluoroethyl)-L-cysteine in rats and mice, Toxicol. Sci. 56 (2000) 414-423.

37. C.L. Potter, A.J. Gandolfi, R. Nagle, J.W. Clayton, Effects of inhaled chlorotrifluoroethylene and hexafluoropropene on the rat kidney, Toxicology and Applied Pharmacology. 59 (1981) 431-440. 
38. W.M. Han, S.-J. Heo, T.P. Driscoll, J.F. Delucca, C.M. McLeod, L.J. Smith, R.L. Duncan, R.L. Mauck, D.M. Elliott, Microstructural heterogeneity directs micromechanics and mechanobiology in native and engineered fibrocartilage, Nat. Mater. 15 (2016) 477-484.

39. N.S. Binulal, A. Natarajan, D. Menon, PCL-gelatin composite nanofibers electrospun using diluted acetic acid-ethyl acetate solvent system for stem cell-based bone tissue engineering, Journal of Sci Polym Ed (2014).

40. S. Bansal, S. Mandalapu, C. Aeppli, F. Qu, S.E. Szczesny, R.L. Mauck, M.H. Zgonis, Mechanical function near defects in an aligned nanofiber composite is preserved by inclusion of disorganized layers: Insight into meniscus structure and function, Acta Biomaterialia. 56 (2017) 102-109.

41. M.L. Tanzer, Cross-linking of collagen, Science. 180 (1973) 561-566.

42. L. Mastropasqua, Collagen cross-linking: when and how? A review of the state of the art of the technique and new perspectives, Eye Vis (Lond). 2 (2015) 19.

43. R.S. Givens, A.L. Yousef, S. Yang, G.T. Timberlake, Collagen cross linking agents: design and development of a multifunctional cross linker, Photochem. Photobiol. 84 (2008) 185-192.

44. J.S. Pieper, T. Hafmans, J.H. Veerkamp, T.H. van Kuppevelt, Development of tailormade collagen-glycosaminoglycan matrices: EDC/NHS crosslinking, and ultrastructural aspects, Biomaterials. 21 (2000) 581-593.

45. C.A. Schneider, W.S. Rasband, K.W. Eliceiri, NIH Image to ImageJ: 25 years of image analysis, Nat. Methods. 9 (2012) 671-675.

46. M. Favata, Scarless healing in the fetus: Implications and strategies for postnatal tendon repair, University of Pennsylvania Dissertation Repository, 2006.

47. R.E. Neuman, M.A. Logan, The determination of hydroxyproline, J. Biol. Chem. 184 (1950) 299-306.

48. B.M. Baker, R.L. Mauck, The effect of nanofiber alignment on the maturation of engineered meniscus constructs, Biomaterials. 28 (2007) 1967-1977.

49. S.-J. Heo, S.D. Thorpe, T.P. Driscoll, R.L. Duncan, D.A. Lee, R.L. Mauck, Biophysical Regulation of Chromatin Architecture Instills a Mechanical Memory in Mesenchymal Stem Cells, Sci. Rep. 5 (2015) 16895.

50. L.A. Gates, J. Shi, A.D. Rohira, Q. Feng, B. Zhu, M.T. Bedford, C.A. Sagum, S.Y. Jung, J. Qin, M.-J. Tsai, S.Y. Tsai, W. Li, C.E. Foulds, B.W. O'Malley, Acetylation on histone H3 lysine 9 mediates a switch from transcription initiation to elongation, J. Biol. Chem. 292 (2017) 14456-14472.

51. J. Schindelin, I. Arganda-Carreras, E. Frise, V. Kaynig, M. Longair, T. Pietzsch, S. Preibisch, C. Rueden, S. Saalfeld, B. Schmid, J.-Y. Tinevez, D.J. White, V. Hartenstein, 
K. Eliceiri, P. Tomancak, A. Cardona, Fiji: an open-source platform for biological-image analysis, Nature Methods. 9 (2012) 676-682. https://doi.org/10.1038/nmeth.2019.

52. R.W. Farndale, D.J. Buttle, A.J. Barrett, Improved quantitation and discrimination of sulphated glycosaminoglycans by use of dimethylmethylene blue, Biochim. Biophys. Acta. 883 (1986) 173-177.

53. S.-J. Heo, S.-E. Kim, J. Wei, Y.-T. Hyun, H.-S. Yun, D.-H. Kim, J.W. Shin, J.-W. Shin, Fabrication and characterization of novel nano- and micro-HA/PCL composite scaffolds using a modified rapid prototyping process, J. Biomed. Mater. Res. A. 89 (2009) 108116.

54. W. Jiang, J. Shi, W. Li, K. Sun, Morphology, wettability, and mechanical properties of polycaprolactone/hydroxyapatite composite scaffolds with interconnected pore structures fabricated by a mini-deposition system, Polym. Eng. Sci. 52 (2012) 2396-2402.

55. G. BaoLin, P.X. Ma, Synthetic biodegradable functional polymers for tissue engineering: a brief review, Sci. China Chem. 57 (2014) 490-500.

56. L. Yang, Z. Jiang, L. Zhou, K. Zhao, X. Ma, G. Cheng, Hydrophilic cell-derived extracellular matrix as a niche to promote adhesion and differentiation of neural progenitor cells, RSC Adv. 7 (2017) 45587-45594.

57. Y.S. Kim, M. Majid, A.J. Melchiorri, A.G. Mikos, Applications of decellularized extracellular matrix in bone and cartilage tissue engineering, Bioeng Transl Med. 4 (2019) 83-95.

58. J.W. Wassenaar, G.R. Boss, K.L. Christman, Decellularized skeletal muscle as an in vitro model for studying drug-extracellular matrix interactions, Biomaterials. 64 (2015) 108-114.

59. G. Schulze-Tanzil, O. Al-Sadi, W. Ertel, A. Lohan, Decellularized tendon extracellular matrix-a valuable approach for tendon reconstruction?, Cells. 1 (2012) 1010-1028.

60. P. Lu, K. Takai, V.M. Weaver, Z. Werb, Extracellular matrix degradation and remodeling in development and disease, Cold Spring Harb. Perspect. Biol. 3, 2011

61. Strong et al., 2015 (A.L. Strong, J.M. Gimble, B.A. Bunnell, Analysis of the Pro- and AntiInflammatory Cytokines Secreted by Adult Stem Cells during Differentiation, Stem Cells Int. 2015, 412467

62. A. Pinheiro, A. Cooley, J. Liao, R. Prabhu, S. Elder, Comparison of natural crosslinking agents for the stabilization of xenogenic articular cartilage, J. Orthop. Res. 34 (2016) 1037-1046.

63. S. Bansal, J.M. Peloquin, N.M. Keah, O.C. O'Reilly, D.M. Elliott, R.L. Mauck, M.H. Zgonis, Structure, function, and defect tolerance with maturation of the radial tie fiber network in the knee meniscus, J. Orthop. Res. (2020).

64. P. Beaufils, R. Becker, S. Kopf, O. Matthieu, N. Pujol, The knee meniscus: management of traumatic tears and degenerative lesions, EFORT Open Rev. 2 (2017) 195-203. 
65. F.T. Moutos, L.E. Freed, F. Guilak, A biomimetic three-dimensional woven composite scaffold for functional tissue engineering of cartilage, Nat. Mater. 6 (2007) 162-167.

66. M. Persson, P.P. Lehenkari, L. Berglin, S. Turunen, M.A.J. Finnilä, J. Risteli, M. Skrifvars, J. Tuukkanen, Osteogenic Differentiation of Human Mesenchymal Stem cells in a 3D Woven Scaffold, Sci. Rep. 8 (2018) 10457.

67. F. Han, S. Liu, X. Liu, Y. Pei, S. Bai, H. Zhao, Q. Lu, F. Ma, D.L. Kaplan, H. Zhu, Woven silk fabric-reinforced silk nanofibrous scaffolds for regenerating load-bearing soft tissues, Acta Biomater. 10 (2014) 921-930.

68. E.A. Makris, P. Hadidi, K.A. Athanasiou, The knee meniscus: structure-function, pathophysiology, current repair techniques, and prospects for regeneration, Biomaterials. 32 (2011) 7411-7431.

69. P.C.M. Verdonk, R.G. Forsyth, J. Wang, K.F. Almqvist, R. Verdonk, E.M. Veys, G. Verbruggen, Characterisation of human knee meniscus cell phenotype, Osteoarthritis Cartilage. 13 (2005) 548-560.

70. L.C. Ionescu, G.C. Lee, G.H. Garcia, T.L. Zachry, R.P. Shah, B.J. Sennett, R.L. Mauck, Maturation state-dependent alterations in meniscus integration: implications for scaffold design and tissue engineering, Tissue Eng. Part A. 17 (2011) 193-204. 
(A)

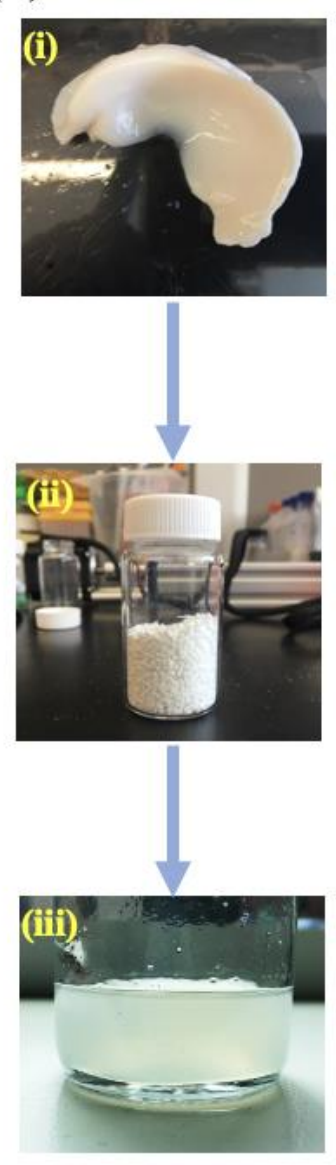

(B)
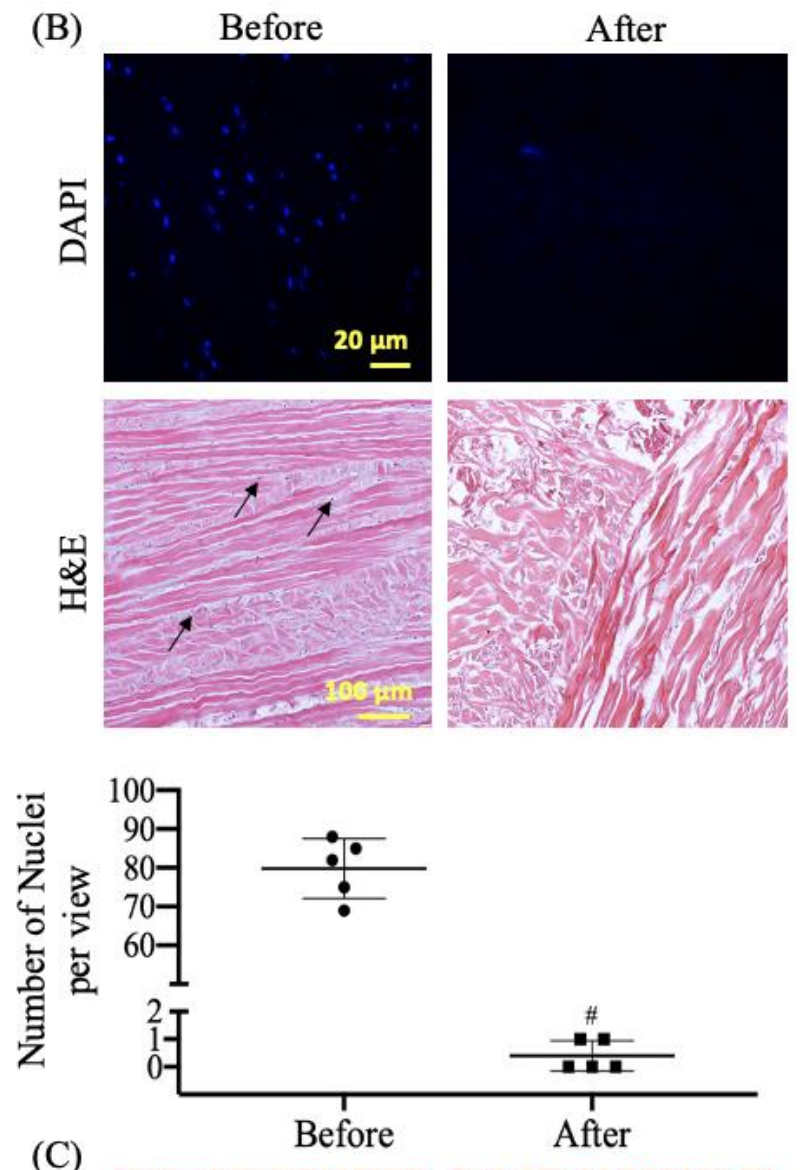

(C)

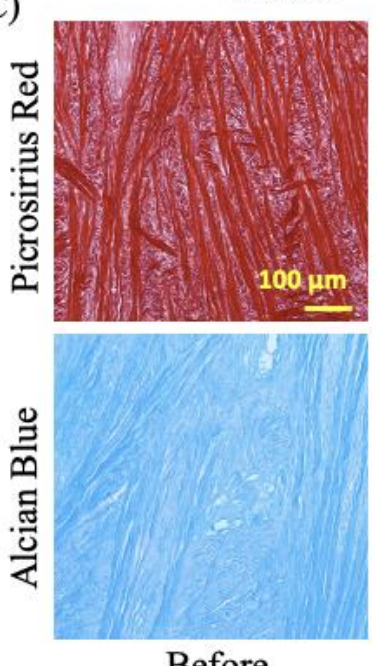

Before

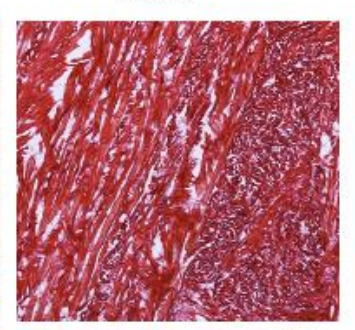

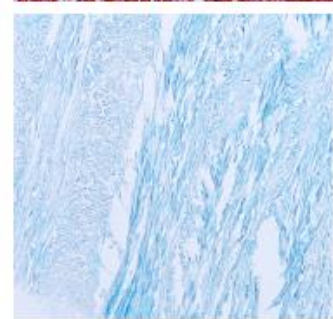

After

Fig. 1: (A) Preparation of electrospinning solution: (i) whole bovine meniscus (ii) lyophilized decellularized meniscus cubes and (iii) ECM in AED solution. (B) Representative images of DAPI staining and quantification of nuclei per view [\#: $p<0.05$ vs. before, $n=5$, mean $\pm S D$, experiments were carried out at least in duplicate], and H\&E staining (arrows: nuclei) before 
and after decellularization. (C) Representative images of picrosirius red staining for collagen and alcian blue staining for proteoglycan content before and after decellularization.

(A)

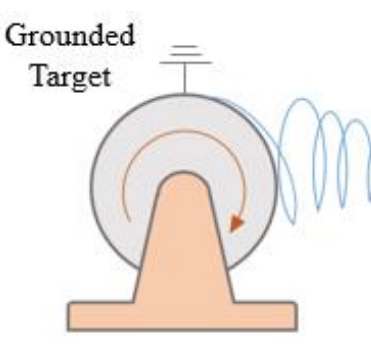

(B)

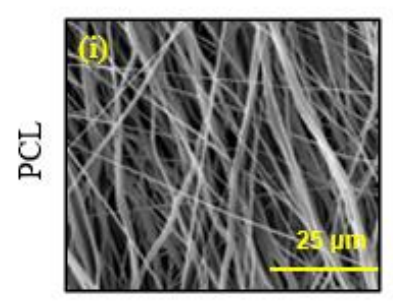

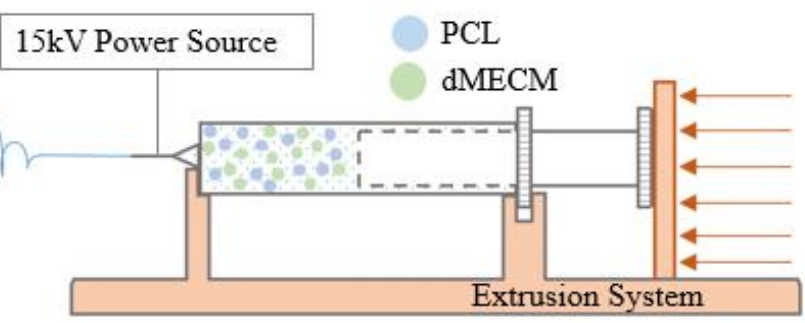

(C)
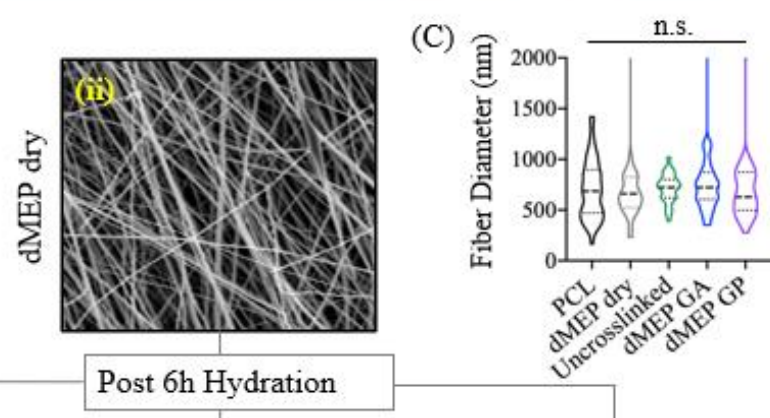

Post 6h Hydration
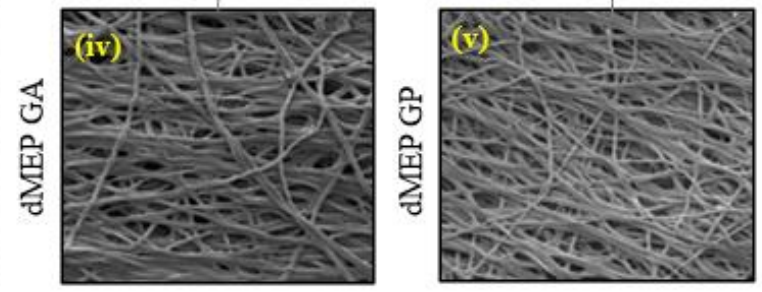

(D)

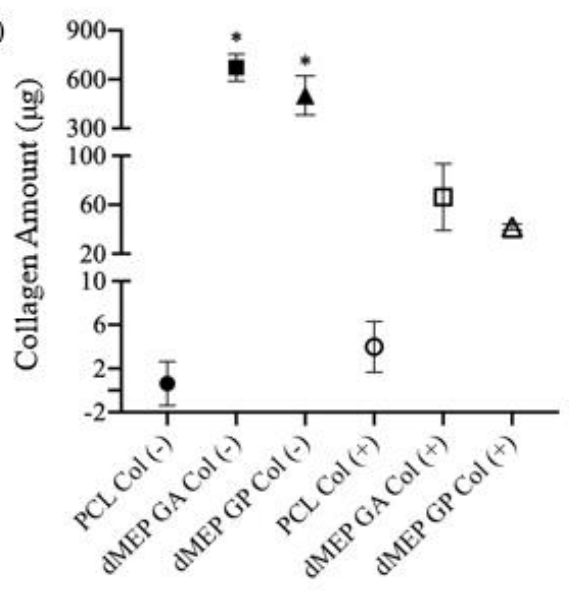

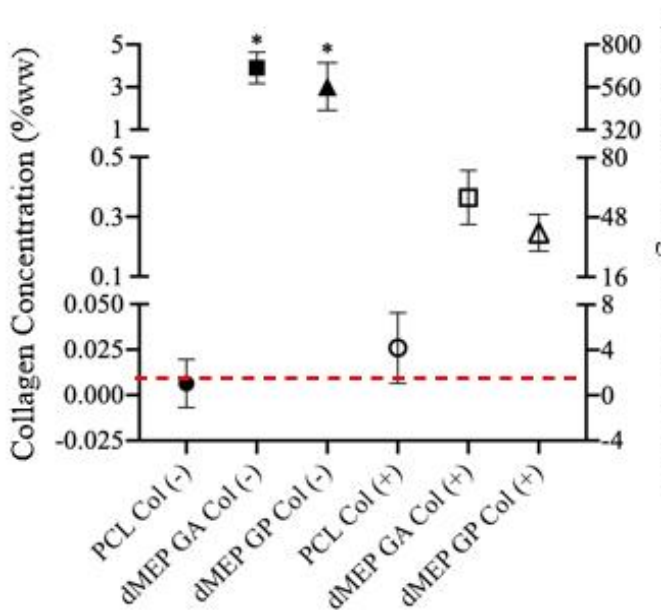

Fig. 2: (A) Diagram of electrospinning of the dMEP mixture; (B) Representative SEM images of (i) 24\% PCL control fibers, (ii) uncrosslinked, dry dMEP fibers, iii) uncrosslinked dMEP, (iv) Glutaraldehyde (GA) crosslinked dMEP fibers, and (v) Genipin (GP) crosslinked dMEP fibers post $6 \mathrm{~h}$ submersion in water; (C) Comparison of PCL and dMEP fiber diameter $[n=50$, dashed line marks median, dotted lines mark 25 percentile and 75 percentile]; (D) Collagen amount and concentration of acellular PCL and dMEP scaffolds before and after $24 \mathrm{~h}$ of $2 \mathrm{mg} / \mathrm{mL}$ collagenase 
type 2 treatment [right $Y$ axis normalization to week $1 \mathrm{PCL}$ group, * $\mathrm{p}<0.05, \mathrm{vs} . \mathrm{PCL}, \mathrm{n}=4$ per group, mean $\pm S D]$.
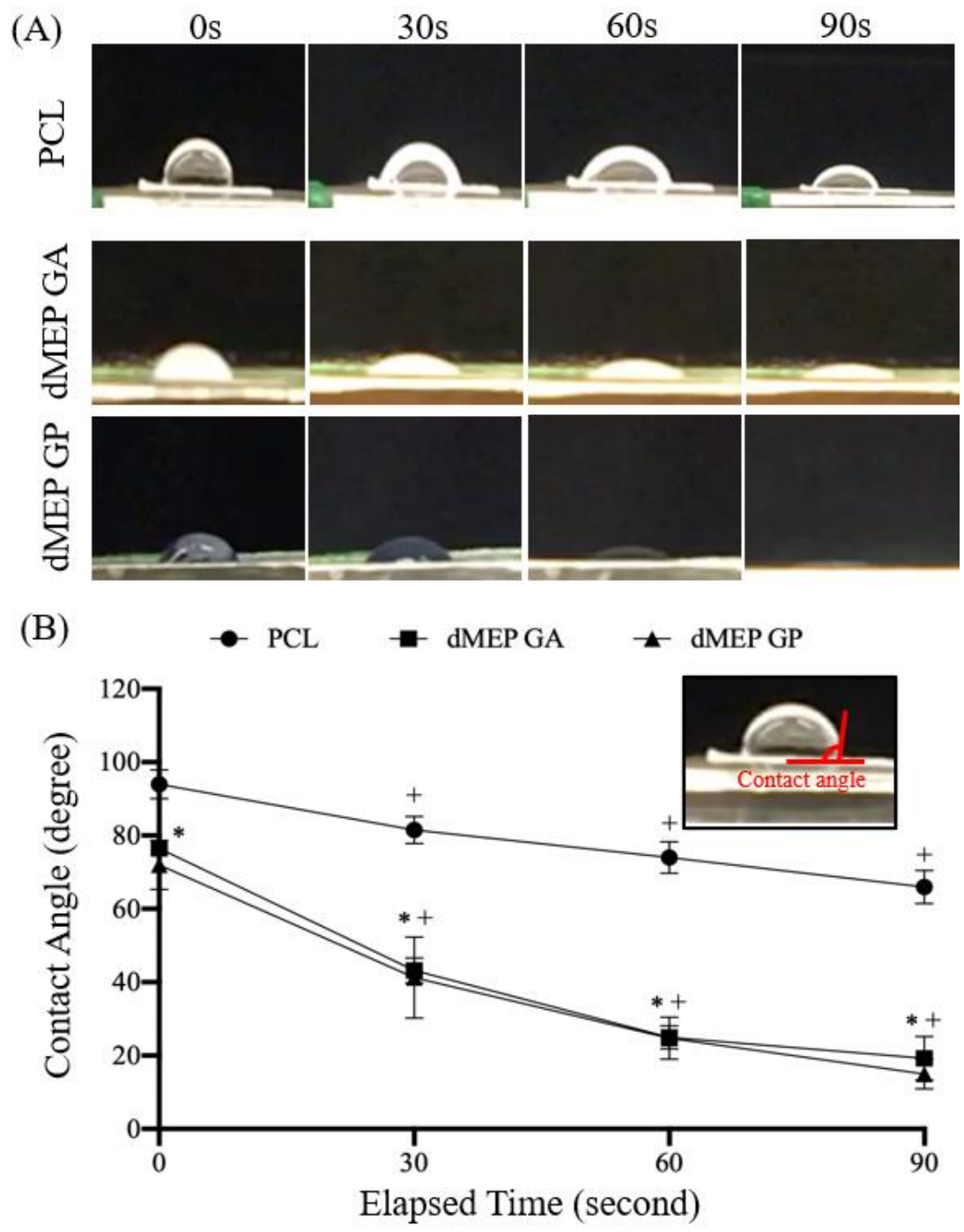

Fig. 3: (A) Representative images of contact angle change on the water drop on 3 groups of scaffolds (PCL control, GA- or GP-crosslinked dMEP) at elapsed time points $0,30 \mathrm{~s}, 60 \mathrm{~s}$, and 90s. (B) Quantification of contact angle changes with time ${ }^{*}: p<0.05$ vs. PCL, $+: p<0.05$, vs. 0 s, $n=4$ per group, mean $\pm S D]$. 
(A)

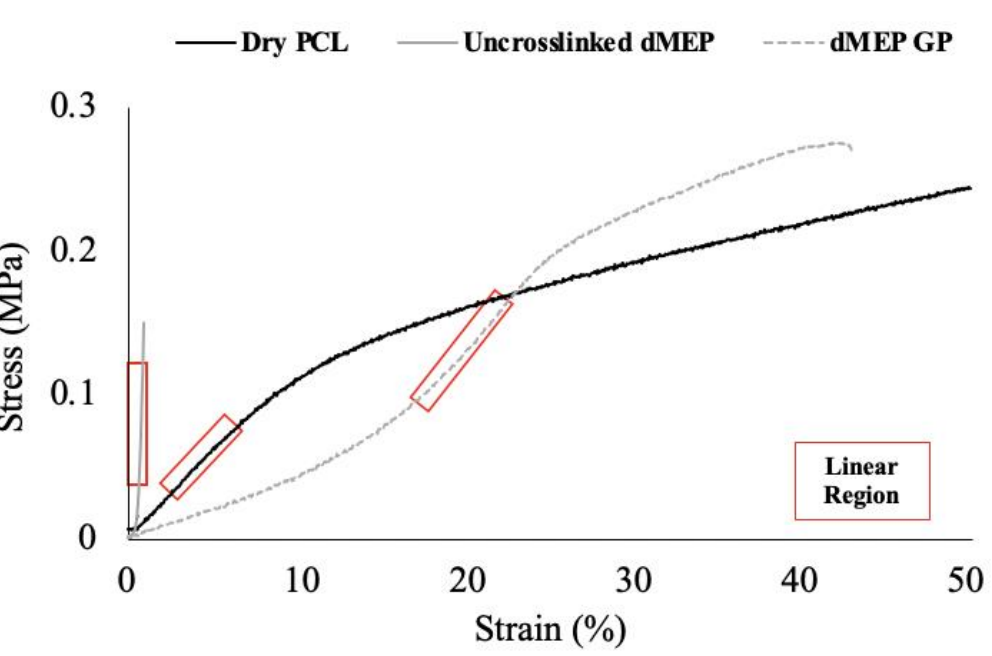

(B) Before Crosslinking (dry)
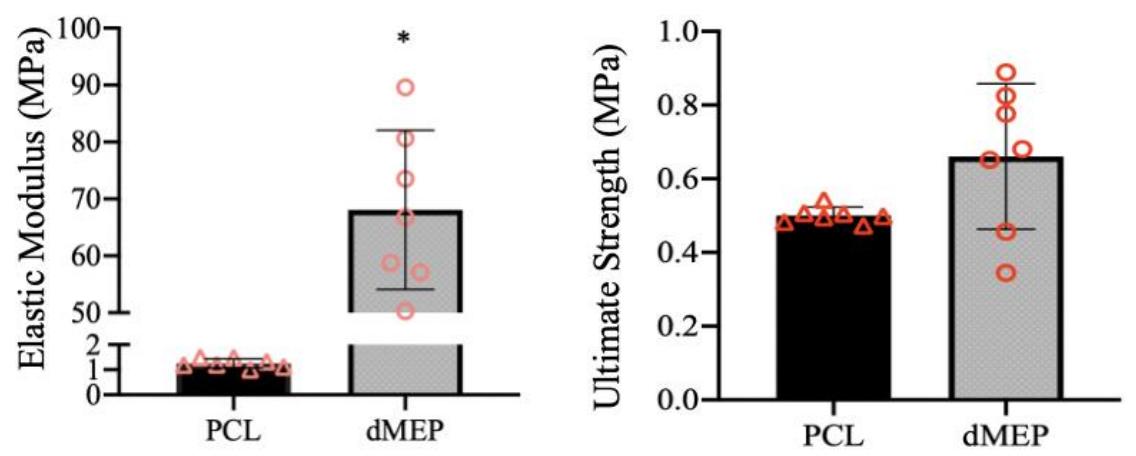

(C) After Crosslinking (wet)
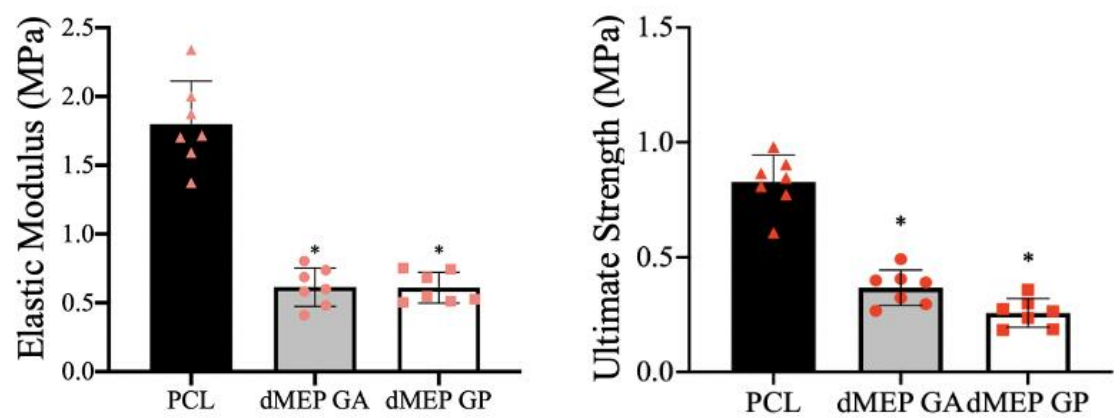

Fig. 4: (A) Representative stress-strain curves of a PCL scaffold, an uncrosslinked dMEP scaffold and a GP crosslinked dMEP scaffold with linear regions labeled. The elastic modulus and ultimate tensile strength of PCL and dMEP scaffolds $(B)$ before and $(C)$ after crosslinking. 
${ }^{*}: \mathrm{p}<0.05$, vs. PCL, $n=6-7$ per group, mean $\pm S D$, experiments were carried out at least in duplicate].

(A)
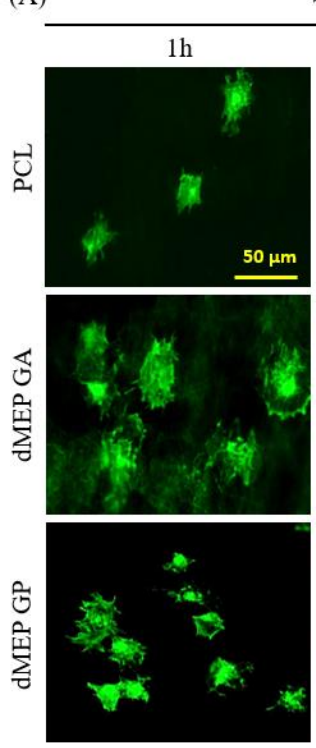
Time after seeding (hour)
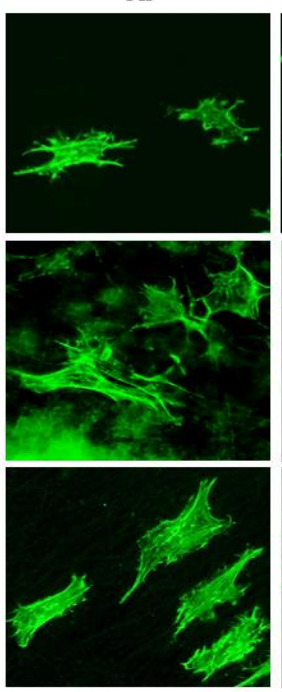

$6 \mathrm{~h}$

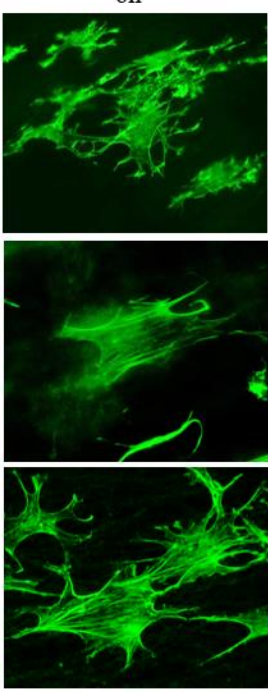

(B)
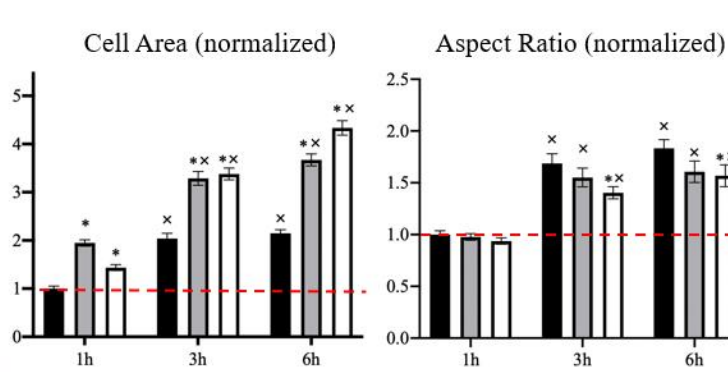

Solidity (normalized)

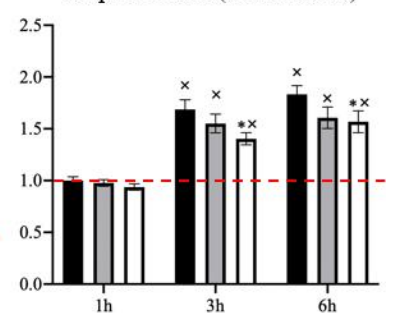

(C) Proliferation (normalized)
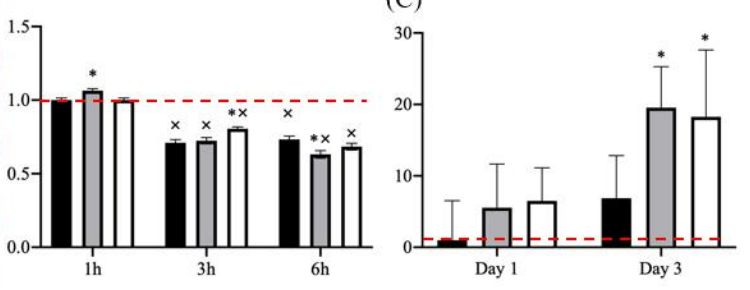

Fig. 5: (A) Representative images of actin staining with Alexa Fluor 488 Phalloidin of bMFCs seeded onto 3 groups of scaffolds, incubated in a chemically-defined growth factor-free media for 1,3 , or $6 \mathrm{~h}$. (B) Quantitation of cell area, aspect ratio and solidity of bMFCs seed onto the scaffolds and incubated for 1,3 , or $6 \mathrm{~h}$. All normalized to the $1 \mathrm{~h}$ PCL group [ ${ }^{*} \mathrm{p}<0.05$, vs. PCL; $\mathrm{x}: \mathrm{p}<0.05$, vs. $1 \mathrm{~h}, \mathrm{n}=27-30$ per group, mean $\pm S E M]$. (C) Absorbance reading at $450 \mathrm{~nm}$ from a CCK-8 assay terminated at day 1 or 3 for bMFCs incubated in the growth factor-free media. Normalized to the Day 1 PCL group. [ $n=6$ per group, mean $\pm S D$ ] 


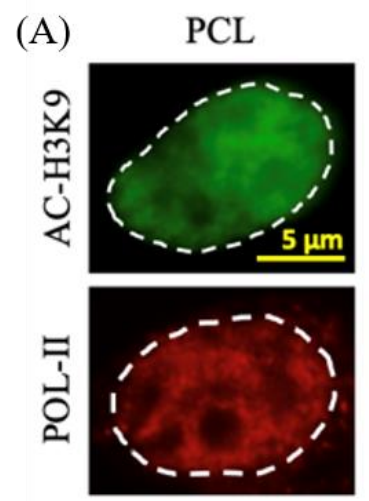

(B)

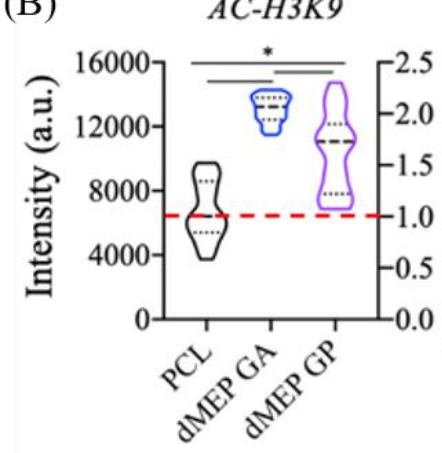

(C)

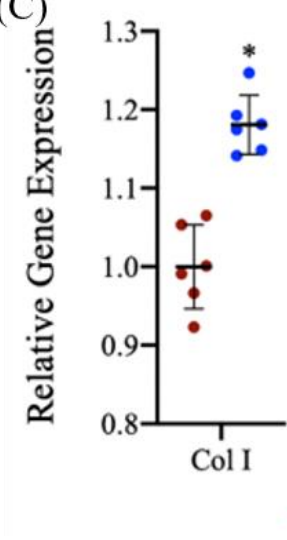

dMEP GA
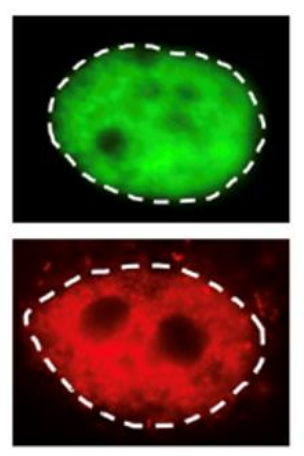

dMEP GP
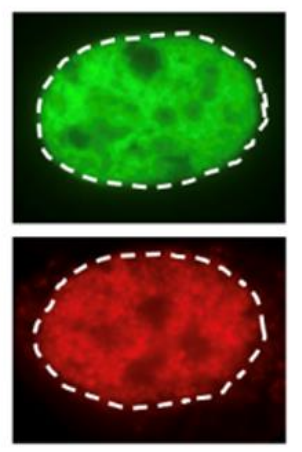

POL-II
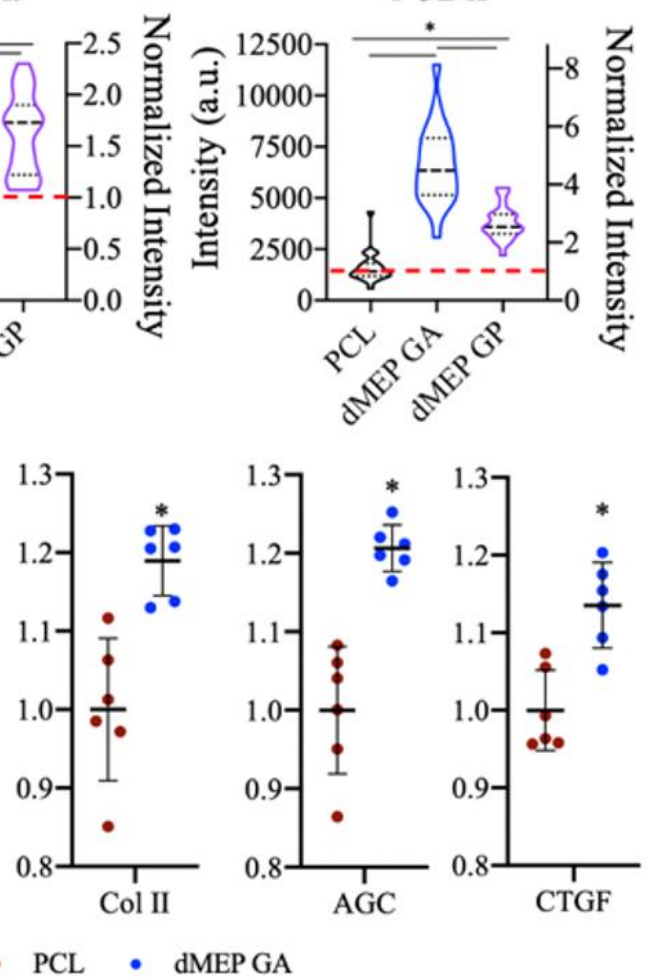

Fig. 6: Representative (A) images and (B) quantification of AC-H3K9 mean intensity and POL-II mean intensity of the nuclei of bMFCs cultured onto PCL, dMEP GA and dMEP GP scaffolds and incubated in growth factor-free media for $24 \mathrm{~h}\left[{ }^{*}: \mathrm{p}<0.05\right.$, vs. $\mathrm{PCL}, \mathrm{n}=18-22$ per group, mean $\pm S E M]$. (C) Level of chondrogenesis-related gene expression relative to GAPDH in bMFCs cultured in growth factor-containing media at day 7 , normalized to PCL group. $\left[{ }^{*}: p<\right.$ $0.05, \mathrm{n}=6$ per group, mean $\pm S D]$. 
(A)

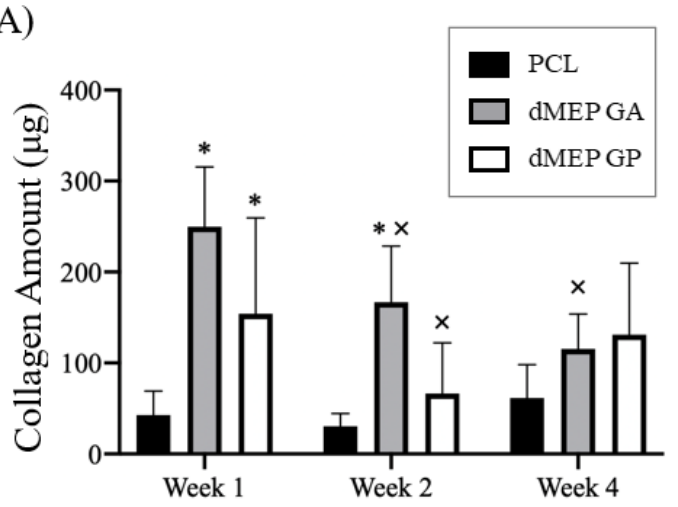

(C)

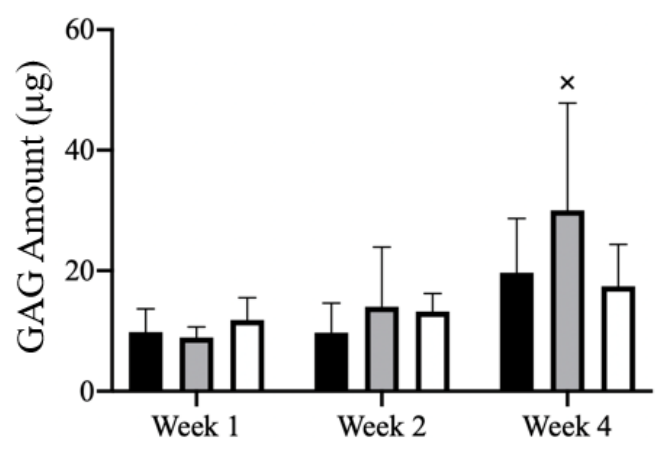

(B)

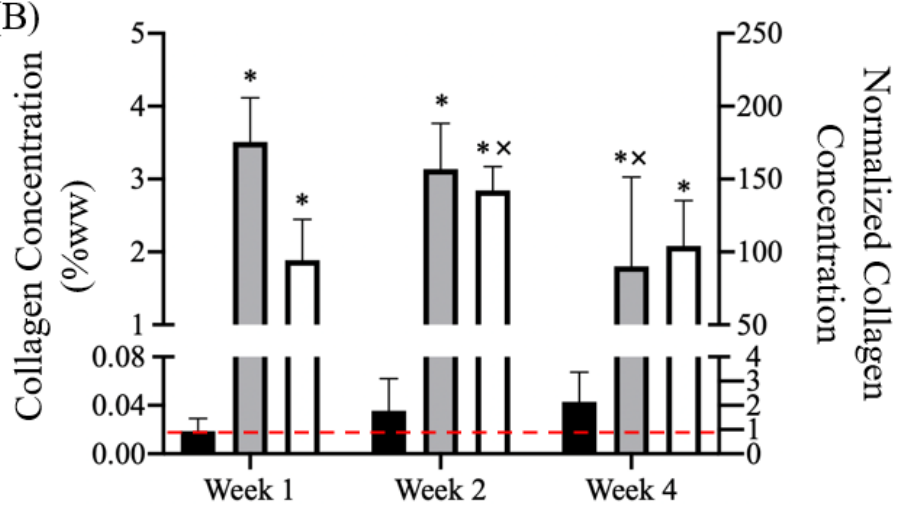

(D)

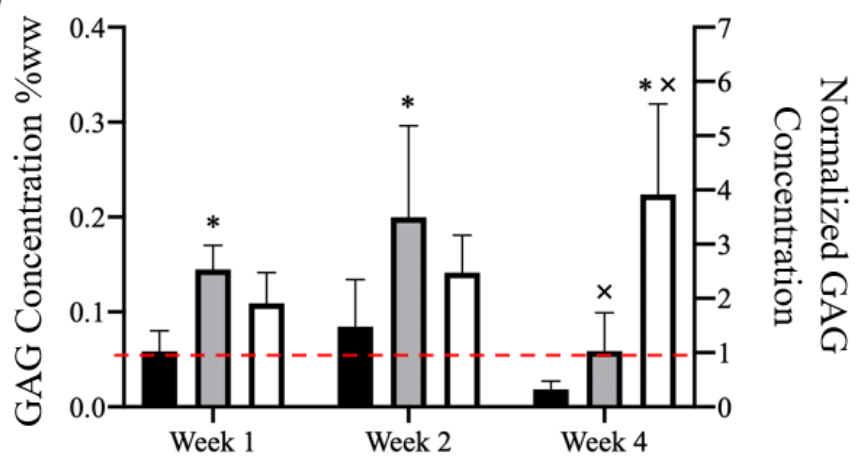

Fig. 7: Quantification of collagen (A) amount and (B) concentration (in \%wet weight, right $Y$ axis normalization to week 1 PCL group) via OHP assay and GAG (C) amount and (D) concentration (in \%wet weight, and normalized to Week 1 PCL group) via DMMB assay of bMFC-seeded scaffolds incubated in growth factor-contained media for 1,2 and 4 weeks. [ ${ }^{*}: p<0.05$, vs. PCL; $x: p<0.05$, vs. 1 week, $n=5-6$ per group, mean $\pm S D]$. 